\title{
Rural Teachers' Continuing Education Model Based On Network Platform Construction
}

\author{
Xu Jiying \\ School of literature of Zhengzhou Normal University \\ Zhengzhou, China \\ liucongjia0607@163.com
}

\begin{abstract}
In recent years, our rural grassroots teachers' continuing education training shows a tendency of vigorous development, with the rapid development of information construction, however, the traditional continuing education teaching training mode is unable to cultivate teachers' potential and strength. This paper expounds three kinds of ideas of the rural continuing education mode, and put forward the feasible solutions to promote continuing education solidly and effectively.
\end{abstract} mode

Keywords—continuing education; network platform; education

\section{INTRODUCTION}

With the reform and development of education, the social demands on the teaching profession have become higher and higher. In the current process of comprehensive promotion of quality education, improving teachers ' professional level, and effectively promoting teachers' professional development have become an important and unavoidable problem in the development of primary and secondary schools as well as colleges and universities. With the advancement of Internet information and education, traditional model of continuing education was impossible to provide sufficient learning to the learner and the opportunities to participate in the society. More and more instructional designers try to use blended learning mode includes a variety of transmission modes. Started in 2001 , B-learning (Blended Learning) has become the hotspot of the education sector.[1]Internet technology and information technology have been applied to continuing education and training, more and more new ways of teaching and research are explored and practiced.

In this process, how to further enrich the digital educational resources, form a sharing mechanism, enhance the level of teachers' proficiency and curriculum implementation, and bring change to education on the basis of this, have become a concern in the process of educational informationized development. The author believes that continuing education is a strong practice, not only need the support of educational theory, but also needs the support of practical knowledge. How to organize teaching is the most meaningful aspect of teaching practice, and only through increasing the teachers ' curriculum implementation, to encourage innovation for the purpose of teaching in order to embody the meaning of quality education. Use this as an opportunity, with the power of the network to further promote the development of continuing education reform is imperative.

\section{PERFECT CONCEPT OF EDUCATION AND TRAINING MECHANISM}

Since the reform and opening up, the effectiveness and implementation of further education for teachers in rural areas has been much concerned has become an important factor restricting the development of rural education. Now, with the implementation of curriculum reform and educational reform, higher requirements have been put forward to teachers especially rural teachers. In the long run, both in the development of the school and in the personal growth of teachers, continuing education has an important role. Continuing education in promoting implementation and success is based on the participation of teachers, only by the school department will not be able to reach the goals.

To smoothly carried out continuing education, first, management layer of school and training schools should give maximum approval and support, including financial support, principal's identity and participation, which can provides a model for the preparations and implementation of continuing education; second, middle layer should provides various support and policy and program description to continuing education, for example implementation steps, and related work process, and note matters and so on. These policies and procedures can be published as handbooks and hand out to teachers, strengthen the confidence and security of teachers; finally, to keep timely, accurate and complete recording every year of primary teachers in rural areas, in order to maintain complete information for later analysis, evaluation, supervision and research basis and normalized it. At the same time introduce a registration system for continuing education. Educational unit shall continuously record the basic situation of professional and technical personnel to receive further education, and as a professional assessment of important content and serve an important basis for licensing and the flow of talent. So whether it is a teacher's school or continuing education training schools can keep abreast of the situation, the problems, and if it had the expected effect. 


\section{MODE OF PRACTICE TEACHING PLATFORM BASED ON} NETWORK

\section{A. Introducing online learning networks system for knowledge development to rural teachers}

To promote professional and technical personnel to understand and grasp the related professional and technical aspects of new theories, new technologies, new methods, and new information. In order to perfect knowledge structure, improve the level of expertise and innovation, people must learn to introduce online training system. Which means to take advantage of traditional learning and e-learning (that is, the digital or e-learning), to develop teachers' leading role of guidance, inspiration, and monitoring the teaching process, also fully reflect the students' initiative, enthusiasm and creativity in the process of study.[2] It stressed that "student-oriented, teacher-led" teaching structure, emphasizes the use of online resources and combines traditional media.[3] Encourages grass-roots teachers to learn online network learning required subjects and professional subjects, follow the spirit of integrating theory with practice, learning, on-demand education, pragmatic principles. Rural teachers' further education hours, middle-level professional teacher periods not less than 86 hours per year (64 hours), of which, professional accounts not less than 60 hours, the public courses need to account for not less than 26 hours; each junior professional technicians no less than 74 hours (56 hours), in which the professional courses of not less than 52 hours, and the public courses to account not less than 22 hours. The training time and goal setting is to help teachers lay the foundation, focus on scientific literacy, strengthen the integration of information technology and the integration of various disciplines to help unity and coherence in writing, specialties and multi-skills.

\section{B. Introduction of MOOC continuing education}

MuKe, referred to as "MOOC", also known as "MOOCs", is a newly emerging online curriculum development model. It originates in the past publishing resources, learning management system and learning management system with more open networks resources into the old curriculum development model. The essence is a large network of open courses; it is to increase the dissemination of knowledge by sharing and cooperative spirit of the individual organization and spread to open courses on the Internet. In the "Mu" mode, curriculum, classroom teaching, all continuing education courses, each teacher's feelings and interactions are showing through real-time rendering. This includes (1) class teaching--"compulsory": classes given by famous teachers and with an camera on, this formed a subject system, and cover related subject of all majors; (2)topic lecture---"elective": tells subject status in the frontier subject and academic hot problem, which can improve related professional students and youth teachers' professional level, widened horizons, and inspired minds; (3) master series---"extracurricular special lecture": records older experts' scholarship experience, philosophy even lifestyle. In this way, each of the teachers participating in the training course can share their interested videos according to their actual situation, and make the most of high quality network resources.

\section{Form a horizontal communication network}

In order to better share high quality educational resources, establish a network of horizontal communication is undoubtedly the best platform for primary teachers pre-service training and in-service training. This article refers to the discussion of network teaching platform based on the Internet, which is the collective name of network teaching software which provides comprehensive support services for online teaching. It is a relatively complete environment which is able to fully and effectively support the networking of teachers' teaching and student's learning.[4] This platform can provide continuing education network with many classroom presentation tools, build teaching environment with Internet features, designed online interactive video, graphics and text, testing, practice, and experience sharing for teachers, and bring fresh Internet learning experiences for teachers. Of course, all this achieved on the assumption that each county must have at least a live classroom, each rural school must have at least a multimedia classroom, bandwidth over $4 \mathrm{M}$ and can watch online classes. Schools which take teachers training education at least have a network classroom with bandwidth above 4M, complemented by good audio video capture device, and can participate in the network of teachers in the teaching and research activities.

\section{REGULARLY CARRY OUT GRASSROOTS TEACHERS INFORMATION TECHNOLOGY TRAINING}

\section{A. Cities and counties in the province achieve "link together"}

Through the " link together " to explore the effective integration of distance education resources and teaching, to promote students to enrich their reading information in a rich network of resources and, greatly enhanced audio and visual effects. " link together " improves teaching efficiency, benefits in teaching the students to carry out quality education and skills training, broaden the students' creative thinking and also help teachers use the Internet to achieve "at the same time preparing lessons, real time interaction, and tests ", to better share quality educational resources and further improve the basic teacher's ability to use information technology.

\section{B. Strengthening the integration of information technology and teaching}

With the development of modern education technology, the use of multimedia and network teaching has been accepted by teachers. The hybrid practice teaching has the incomparable advantage, it designs theme activities in the two face-to-face and online learning environments, and operate practical teaching mode of action.[5] It not only help students to apply modern network technology to learn theoretical knowledge, but also requires students to practice in feeling, cognition and use knowledge to solve practical problems. It can be more intuitive, livelier to realize teaching interaction, and create a good teaching and learning atmosphere. Under the situation of grassroots teachers' poor information technology and low level computer operation, people should fully promote the mutual promotion of the education of information technology and teaching, to implement the information technology into the whole process of education teaching, gradually change the 
original education teaching process and pattern, so as to further improve the ability to control the classroom, also, to change students' passively accept learning, finally to improve teachers' classroom implementation and achieve the goal of improving the teaching quality and efficiency.

\section{Improve the ability of teachers to operate the platform application software}

The microera of information pluralism has come, with education's informationization and the Internet permeate the real life, this kind of teaching, which takes video as the main carrier and presentation method, is more common in the teaching form of subject knowledge points, difficult problems and experimental operation. This puts forward higher requirements for teachers' information literacy. For teachers who use "class pass", we should be able to quickly and efficiently retrieve and locate the fast information from the world's various world, not only can the retrieval efficiency be improved, and there is more time to prepare the materials, complete the preparation task. Teachers can obtain sufficient information from these resources according to their specific discipline requirements and teaching practices. The screening and sorting of these information can best test teachers' information integration ability.

\section{CONCLUSION}

In order to make the classroom information fall to the rural education,break the limits of time and space, let the students enjoy the best quality education resources, the grass-root rural teachers in the teaching process, in addition to the teaching of knowledge, it is also necessary to explore how to integrate the cultivation and quality of students' ability into the normal teaching. If the teacher can take the specific teaching content of each course and the learning situation, the teaching design, material, practice test and teaching reflection of the main content of the teaching will be made into a short teaching video, this is very much in line with the online age learner's attention mode and online teaching technical requirements, ability to motivate students to learn enthusiasm, develop personalized learning. Therefore, education's competent authorities primarily take the lead in basic computer training and electronic whiteboard training for rural primary teachers, it is also urgent to organize information literacy training and education, it then provides the best protection from capital, technology and talent, make sure the classroom teaching gets the necessary resources and information.

\section{REFERENCES}

[1] Wang Youmei,DengDan.The sharing teaching method of the age of dundan Web2.0: connotation,technology and strategy[J]. China phone education,2013(1):16-22.

[2] He Kekang. TPACK - new development of approach and method research of "information technology and curriculum integration" in the United States(top) [J]. Research on education,2012(5):5-10.

[3] He Kekang. The analysis of American information technology and curriculum integration theory and the construction of new integration theory China phone education,2008(7):1-10.

[4] Wang Zhijun,Yu Shengquan. Evaluation of online teaching platform based on EduTools[J]. Modern remote education research,2010(4):73-78.

[5] FengWei,Zhang Zhiyong. Research on the exploration of mixed practice teaching[J]. China higher education,2012(2):46-48. 